\title{
Synoicismo: \\ Controle político através da unificação geográfica da Ática
}

\section{Maria Regina Candido}

Universidade do Estado do Rio de Janeiro

Através da historiografia francesa, podemos perceber que Pierre VidalNaquet, no livro Economies et Sociétés em Grece Ancienne, analisa o período de Sólon com ênfase no processo de colonização visando estabelecer entreposto comercial/emporion no norte da Síria na regiáo de Al Mina e no Egito com a polis de Naukratis, regióes identificadas como lugar de trocas comerciais para assegurar a importação de cereais, metais e produtos agrícolas. Segundo, VidalNaquet, no período do VI século a. C., a crise agrária despertou nos atenienses uma maior atenção em relação aos problemas com o abastecimento de alimentos. Sólon interdita a exportação de qualquer produto agrícola ateniense com exceção de vinho e óleo, buscando assegurar o controle das rotas pelo Mar Negro ${ }^{1}$.

Em relação à crise econômica do período arcaico, a questão está relacionada à distribuiçáo desigual da terra que gerou o descontentamento e reivindicaçôes de parte dos integrantes das poleis. Várias regiōes da Grécia foram vitima de superpovoamento devido à queda no índice de mortalidade. $\mathrm{O}$ fato resultou na insuficiência de produção da terra associada à prática de divisão da terra do pequeno proprietário aos herdeiros, reduzindo o espaço de cultivo levando-o à pratica da agricultura de subsistência ${ }^{2}$, ou seja, a terra náo produzia excedentes necessários para efetuar as trocas comerciais, ofertar aos deuses e promover o dote para casar a filha.

$\mathrm{O}$ autor demarca que o único caso de crise agrária do período arcaico que chegou até a atualidade foi o de Atenas, cujo elemento essencial foi a existência dos hectémoroi, grupo de atenienses propenso a se tornar escravos por

\footnotetext{
${ }^{1}$ Pierre, VIDAL-NAQUET. et alli. Economies et Sociétés em Grece Ancienne. Paris: Armand Colin, 2007, p.88.

${ }^{2}$ Ibidem, p.74.
} 
dividas devido ao débito com os aristhoi. A solução de Sólon reflete a ideia de comunidade, a reforma atingia unicamente os atenienses, excluindo os estrangeiros, escravos e outros, o retorno dos hectémoroi a suas terras tornou-os pequenos proprietários livres e os demais se tornaram artesãos ceramistas ${ }^{3}$.

A explicação do autor pouco esclarece a formação dos hectémoroi e também não menciona sobre os hóroi, os demarcadores da divida, e não menciona sobre a negociação de Sólon em relação às mudanças sobre os pesos e as medidas. A explicação fica em nível das estruturas, fato que dificulta a compreensão da conjuntura sociopolítica conflituosa de Atenas no período arcaico.

A pesquisadora Claude Mosse no artigo Comment sélabore um mythe politique: Solon, père fondateur de La democratie athénienne, publicado na Revista dos Annales (mai-juin, 1979) nos esclarece como se elaborou, a partir do $\mathrm{V}$ século, a imagem de Sólon como fundador da democracia ateniense. A autora acrescenta que as leis promulgadas por Sólon foram constantemente evocadas pelos oradores áticos junto à política de Atenas no século IV a. C. visando recriar a imagem do legislador como pai fundador da democracia ${ }^{4}$. Claude Mosse constrói as suas reflexóes políticas em diálogo e em homenagem às consideraçôes de Moses Finley, presente na publicação The use and abuse of history (1975).

A afirmação da autora nos leva ao questionamento sobre o período em que podemos identificar o estabelecimento da democracia: a partir de Sólon ou de Clístenes? Segundo a autora, a imagem de Clistenes como fundador da democracia ateniense não pertence ao IV século a. C., nesse período ele foi considerado como restaurador do regime político estabelecido por Sólon (ISOCRATES, Aeropagitico, 16). Aristóteles credita que Clistenes não hesitou em acrescer o número de cidadáos junto a sua hetaireia, sendo considerado o responsável pela degradação da democracia dos ancestrais estabelecida por Sólon (ARISTOTELES, Politica, 1275b35).

\footnotetext{
${ }^{3}$ Ibidem, p.90.

${ }^{4}$ Claude, MOSSE. Le Mythe de Solon et La démocratie athénienne. In: Annales: Ėconomies, Société, Civilisations (34º année, Mai-Juin 1979). Paris: Armand Colin, 1979. p.425.
} 
Claude Mosse, no inicio do seu artigo, sugere-nos que o conflito que opôs demos e aristocracia provem de uma situação social grave relacionada à terra. De acordo com a poesia de Sólon, parte da terra ática seria demarcada com os hóroi que indicavam serem aquelas terras e seus habitantes submetidos à servidão, ou seja, a escravidão por divida. A outra parte da terra havia sido incorporada ao patrimônio dos aristhoi pelo fato de seus habitantes, ameaçados pela escravidão devido à dívida contraída, terem optado por escapar à servidão, deixando a terra e seguindo para o exílio ${ }^{5}$. Sólon, eleito arconte, arbitrou o conflito entre os pobre/penetés e os ricos/plousoi. Os termos de identificação eram aplicados no século IV a. C., no período arcaico, em que os pobres seriam os hectemoroi qualificados como camponeses dependentes das terras dos ricos proprietários e obrigados ao pagamento de uma taxa de aluguel da terra - o problema da seisachteia. Fato que levou Sólon a retirar os marcos/-hóroi e abolir as dividas/chreon apokope $e^{6}$.

No texto, a autora argumenta que Sólon teria colocado fim a possibilidade de stasis ao promulgar as leis para os aristhoi e os não-aristhoi visando trazer ambos ao consenso. Ao redigir a lei, percebe-se a presença dos termos themis (leis dos ancestrais), diké (justiça dos homens e escrita em código de lei) e a politeia (definida como um conjunto de leis que visava restabelecer a constituiçáo dos ancestrais, ou seja, a themis) ${ }^{7}$. O retorno às leis dos ancestrais deixa transparecer que Sólon não buscou inovaçóes, e sim restabeleceu uma ordem política e social que, segundo a autora, havia sido estabelecida em período anterior a stasis.

Claude Mossé reconhece que a ação de Sólon permitiu a liberação dos hóroi, retornando parte dos atenienses para as atividades da agricultura de poucos rendimentos - a agricultura de subsistência. Entretanto, a recusa do legislador em realizar a divisão das terras áticas entre os indivíduos sem terras promoveu o acréscimo do número de thetas, ou seja, homens livres que não pertenciam à aristocracia e não eram proprietário de terra, constituindo uma

\footnotetext{
${ }^{5}$ Ibidem, p.426.

${ }^{6}$ Idem.

${ }^{7}$ Ibidem, p.427.
} 
considerável máo de obra livre a ser direcionada para outras atividades de trabalho como oleiro e artesão ${ }^{8}$. Diante dos poucos recursos adquiridos com o trabalho alternativo (tais como a agricultura e o pastoreio), os thetai do período arcaico não participavam da defesa da polis devido a sua incapacidade de custear os seus armamentos, como o faziam os integrantes da falange dos hoplitai.

O estabelecimento das classes censitárias ratifica a existência de uma hierarquia que definia a participação política de acordo com os rendimentos e riqueza. Entretanto, a questão não suscita dúvidas em relação aos hippeis e aos zeugitas que integram o censo soloniano, ambos pertencem à categoria guerreira cuja responsabilidade seria a defesa da polis cuja diferença está na posse ou não de cavalos. Entretanto, Tucídides (I, 2-6) ao afirmar que em períodos remotos a região da Ática, por pobreza de sua terra, foi habitada sempre pelos mesmos homens e sem ser afetada por perturbaçóes como as demais cidades que aumentaram a sua população e por causa da migração resultando em expulsóes e guerra pela disputa pela terra. Mas tem aqueles atraídos pelas medidas de Sólon cujos descendentes foram resultados de casamentos mistos, pois os filhos de mães estrangeiras ainda não estavam excluídos da cidadania, tendo em vista, que a proporção de migrantes era pequena no VI séc. a. C., pois Sólon regulariza e integra o migrante de posse no grupo censitário identificado como pentacossiomedina: consideramos que o termo requer a necessidade de analise e esclarecimentos.

O tema sobre a falange dos hoplitai foi debatido por M. Detienne no artigo La Phalange: Problèmes et controverse no livro de Jean- Pierre Vernant intitulado Problemes se La guerre em Grece ancienne (1968), no qual o autor destaca o novo tipo de armamento de combate adotado no século VII a. C. composto de elmo, armadura de bronze, panóplia e na máo esquerda tem um escudo redondo com dupla alça interna e na mão direita porta uma longa lança, equipamento que detém um custo pago através da rendimento agrário. Para Vernant, a formação da falange hoplítica interferiu na estrutura política da polis ao promover a ruptura revolucionária da participação da aristocracia

${ }^{8}$ Ibidem, p.429 
guerreira tradicional, cuja atividade se condensa na luta individual. A nova formação de combate se opóe a essa forma de luta por propor uma ação coletiva e náo de feitos heroicos individuais, mas do grupo de homens submetidos à mesma disciplina de ordem, combatendo o inimigo em conjunto formando um só corpo?.

A abordagem de M. Detienne não permite identificar quem seriam estes cidadãos que compóem a falange dos hoplitai, fato que nos aproxima do artigo de Pierre Vidal-Naquet intitulado La tradition de l' hoplite athenien na qual nos informa que estes seriam homens com direito de cidade pelo fato de terem passado pelo processo de inscrição no registro do demos/lexiarchicon grammateion com a idade de dezesseis a dezoito anos. Esse registro estava presente em todos os demoi e tinha por objetivo identificar o futuro cidadáo que prestou o juramento no Ritual da Efebia de jamais abandonar o companheiro de armas, defender com a vida o solo sagrado dos ancestrais, obedecer aos magistrados e as leis da polis.

Para Kurt Raaflaub, a falange dos hoplitai tem as suas raízes embrionárias em Homero, porém o seu processo de desenvolvimento se materializa no VII século no qual foi marcante o seu impacto, coesão e união dos guerreiros que formavam um bloco de ataque e defesa. A falange dos hoplitai lutava de forma estritamente coordenada e disciplinar, unidos ombro a ombro, escudo a escudo ${ }^{10}$.

O processo de instauração da falange dos hoplitai não constituiu uma revolução política e social ${ }^{11}$, a "republica" dos hoplitas nos aponta para diversas possibilidades de reflexão, a saber:

1. A falange era essencialmente comunitária, dependia da cooperação e do principio igualitário, ou seja, a elite e o segmento social emergente lutavam lado a lado em defesa do mesmo espaço territorial - a polis.

\footnotetext{
9 Marcel, DETIENNE. La Phalange: Problèmes et controverse. In. Jean-Pierre, VERNANT. Problemes de La guerre em Grece ancienne. Paris: Ed. École dês Hautes Études en Sciences Sociales, 1968.p.167.

${ }^{10}$ Kurt, RAAFLAUB. Origins of Democracy in Ancient Greece. Berkeley: University California Press, 2007.p.35.

${ }^{11}$ Ibidem, p..36.
} 
Os integrantes da falange tiveram que aprender a confiar uns nos outros para a efetiva ação em conjunto. $\mathrm{O}$ sentimento de comunidade deixa de ser pelo prestigio, nascimento, nome de família e demais distinçóes individuais.

2. A luta dos hoplitas não passava pela aristocracia intitulada aristeiai, ou seja, os integrantes das famílias jônias dos quais emergiram o imaginário social da figura dos heróis fundadores. Heróis como Aquiles, Ajax, Pátroclos entre outros heróis gregos que alcançaram o prestigio devido às vitórias em combates individuais cantados nos poemas épicos. Nessa nova configuração, a vitória cabia ao coletivo no qual todos os hoplitas tinham a possibilidade de serem reconhecidos como os melhores, ou seja, como aristhoi e a arete, excelência do guerreiro individual, passou a ser estendido à republica dos hoplitas.

3. Cabia à comunidade poliade supervisionar o processo de treinamento dos hoplitas que se iniciava com o jovem através do Ritual da Efebia. Acrescentamos a prerrogativa de decidir quando e onde deveria se desenrolar o combate. Embora a luta da aristocracia guerreira associada às incursóes de caráter privado contra regióes vizinhas ainda ocorressem, náo podemos deixar de considerar que a falange dos hoplitai formava a principal força guerreira das polis gregas a partir do período arcaico.

O embate dos hoplitas no período arcaico estava, de certa forma, condicionado ao crescimento populacional do VIII e VII a. C. Esse fato fomentou a luta entre regióes devida à escassez de terra, a emergência do conceito de territorialidade e a necessidade de delimitar e fixar fronteiras terrestres. Em período de paz, a busca de prestígio e glória do guerreiro adquirida em combate individual materializou-se na competitividade dos jogos olímpicos com as suas diversas modalidades de luta e disputa. Tal constatação permite aos helenistas especularem que os aristhoi, integrantes das famílias eminentes, buscaram nas atividades esportivas a configuração do ideal heroico composto pela arete, geras atributos que se desenvolvem sincronicamente e em paralelo ao conceito de igualitarismo da falange dos hoplitai ${ }^{12}$.

${ }^{12}$ Idem. 
O lexiarchicon grammateion qualifica-se como registro dos hoplitas, pois tinha como função informar ao demos os cidadáos capacitados de promover o próprio equipamento, portar suas armas, integrar o regimento de infantaria pesada e promover o ataque/defesa da polis ${ }^{13}$. Logo, eles pertencem à terceira classe da hierarquia soloniana, os zeugitas e formam a armada de pequenos proprietários que o autor denomina de república dos hoplitai composta por cidadãos-camponeses-soldados que detêm capacidade de pagar por seus equipamentos de combate. Os integrantes da "república" dos hoplitai se identificam com os valores e preceitos defendidos pela aristocracia guerreira, porque eles buscam ser os melhores dos guerreiros em combate em conjunto.

$\mathrm{O}$ questionamento que transita pelo nosso debate se configura na ausência de informação de inscrição no lexiarchicon grammateion sobre o segmento social dos thetas que atuavam na frota naval ateniense. Nicole Loraux defende que os obituários seguiam o modelo de catalogo hoplitico, porém a democracia não negaria ao cidadão de plenos direitos a honra de partilhar a sepultura dos athenaion hoide apethanon/ entre os atenienses mortos ${ }^{14}$. Os thetas que atuavam na frota naval ateniense faziam parte das inscriçóes do Athénaioi. Vidal-Naquet concentra a sua atenção na formação do soldado hoplita, porém afirma que nada nos permite concluir que os thetas eram excluídos da lista de combatentes mortos na guerra ${ }^{15}$.

Em sequência à nossa pesquisa, percebemos a escassez de dados referentes à atuação política do segmento social thetas na frota naval ateniense a partir da historiografia francesa. A resposta às indagaçóes formuladas nessa pesquisa nos aproximou da abordagem realizada pelo o que denominamos de nova historiografia anglo-americana que prioriza apreender as açóes políticas de um determinado segmento social e a identificar o lugar de onde tais açóes políticas se elaboram.

\footnotetext{
13 Marcel, DETIENNE. La Phalange: Problèmes et controverse. In. Jean-Pierre, VERNANT. Problemes de La guerre em Grece ancienne. Paris: Ed. École dês Hautes Études en Sciences Sociales, 1968.p.220.

${ }^{14}$ Nicole, LORAUX. Invenção de Atenas. Rio de Janeiro: Editora 34, 1994.p.54.

${ }_{15}$ Pierre, VIDAL-NAQUET. et alli. Economies et Sociétés em Grece Ancienne. Paris: Armand Colin, 2007.p.219.
} 
As duas tradições historiográficas mantêm uma relação de dialogo entre Moses Finley e Claude Mossé ao defenderem que a ação política se elabora em lugares fora dos quadros institucionais. Antes de entrarmos nessas consideraçóes sobre a ação política dos thetas analisadas a partir de historiografia anglo-americana, podemos revisitar a formação da historiografia francesa da qual grande parte dos pesquisadores brasileiros somos sectários.

Ao abordamos o político como lugar do poder, temos que admitir que tal perspectiva advinda do século XIX com Griechische Staatskunde que analisa o político a partir das instituiçóes cívicas gregas. Tal perspectiva foi renovada através da equipe liderada por Mogens H. Hansen no Copenhagen Polis Center. Atribui uma relativa autonomia das instituições em relação à esfera religiosa e se afasta das consideraçóes de Fustel de Coulanges na obra La Cité Antique (1864). A equipe de Mogens H. Hansen elaborou um inventário de todas as cidades-estados conhecidas do mundo grego, ação que resultou na publicação do Inventory of Archaic and Classical Poleis (2004).

Outra possibilidade de abordagem do político está em apreendê-lo como inserido/ embedded no universo social grego. Nessa perspectiva, as duas tradições historiográficas mantém uma relação de proximidade na figura Moses Finley e Claude Mossé ao defenderem que a ação políticas se elabora em lugares fora dos quadros institucionais com os quais interagem visando fornecer uma forma legal para as relaçôes de forças existentes na sociedade ${ }^{16}$. VidalNaquet insere o conceito de instrumental político ao qual define como ação dos gregos para a maioria dos gregos, os direitos políticos constituem-se como um instrumental de ação pelo fato de ser um meio para se atingir um fim ${ }^{17}$.

Claude Mossé ratifica o conceito de instrumental político ao trazer ao debate o jogo das relaçóes de clientelismo no funcionamento da vida publica no qual as assistências socioeconômicas da elite política permitem esclarecer as estruturas de dominação que condicionam a vida política da democracia ateniense. Tal perspectiva, vai de encontro ao grupo de Morgen H. Hansen ao defender a fragilidade das demais instituiçóes sociais e por trazer o exercício de

\footnotetext{
${ }^{16}$ Ibidem, p. 272.

${ }^{17}$ Ibidem, p. 275.
} 
poder relacionado a interesses que lhes são estranhos. Por outro lado, Morgen H. Hansen esvazia as práticas sociais e as relaçóes de sociabilidade presentes nos grupos definidos pelas fratrias na definição da cidadania, nas associaçóes de cultos domésticos, na definição dos status social da aristocracia,na relação de philia entre os grupos de aristhoi que compóe as hetaireiai, nas açóes que no conjunto excedem a dimensão institucional.

A abordagem que relaciona o político ao viés antropológico tende a identificar as açóes políticas através das interações sociais inseridas não no conjunto da comunidade cívica, tese defendida por Louis Gernet, Jean-Pierre Vernant e Pierre Vidal-Naquet. O que demarca o grupo está na elaboração da antropologia do político em relação a outros domínios de atividades como a esfera religiosa, a educacional e a ritualização da sociedade inserida na documentação alternativa ao texto impresso, ou seja, o uso das imagens como suporte de informação. A perspectiva antropológica dialoga com Max Weber e Emile Durkheim e defende que a abordagem das instituiçóes políticas gregas somente permite serem compreendidas em relação ao conjunto das interaçóes sociais. O grupo retoma as abordagens de Fustel de Coulanges ao trazer as consideraçóes da proeminência do religioso sobre o político, fato que resultou em inúmeros trabalhos classificados como político-religioso.

A renovação da abordagem política na historiografia francesa nos remete a Nicole Loraux ao inserir em suas análises a perspectiva antropológica do político afastada dos aspectos ritualísticas pelo fato de imobilizar o tempo cívico que nos remete a generalização de etapas, interação entre status sociais opostos e a tradição historiográfica de praticas sociais em tornos de sacrifícios, guerra e casamento. A autora revisita a tradição institucional associada à abordagem antropológica que a permite construir o imaginário social da polis dos atenienses, no qual a sociedade se constrói através do discurso como uma comunidade poliade visando minimizar o conflito ao evidenciar as stasis entre os segmentos sociais através do embate político, recuos e negociação na polis dos atenienses.

A partir dessas perspectivas, nos aproximamos da tendência historiográfica anglo-americana que define o espaço jurídico afastado do 
modelo de imposição normativa, mas como um espaço construído através da negociação. As normas passam a ser pensadas como o resultado de uma serie de convençôes provisórias que visam assegurar a coesão na polis dos atenienses. A polis de Atenas fabrica lugares, ou seja, forja lugares comuns a todos nos quais se estabelecem as mediaçôes visando minimizar as tensóes existentes entre os diferentes segmentos sociais que circulam e interagem na sociedade formando a chamada democracia dos atenienses. Os pesquisadores Vincent Azoulay e Paulin Ismard no artigo Les lieux Du politique dans l'Athénes classique propóe o estabelecimento do dialogo entre as duas tradiçóes historiográficas através da proximidade de Josiah Ober e Nicole Loraux que questionam se o conflito social seria um sintoma de doença de uma sociedade ou a ação conflituosa tornara-se um fenômeno necessária para manter o equilíbrio político constantemente ameaçado. Estabelecendo uma leitura atenta das duas vertentes historiográficas, verificamos que por vezes elas tornam-se complementares. Como exemplo, vamos explicitar a abordagem sobre a seisachtéia empreendida por Sólon no período em que se tornou legislador de Atenas e associada à ação de Clístenes.

A Reforma Territorial de Clístenes nos permite revisitar o debate em torno do processo de unificação geográfica da Ática no qual podemos cotejar indícios da formação do segmento social de poucos recursos, os thetai e parte da população identificada como náo integrantes das phratrias dos atenienses assim como abordar, de forma breve, o estado atual da questão sobre o sinoecismo ático.

O tema tem sido também objeto de análise e critica realizada por Stuart Dawson ao considerar inadequado atribuir a existência de sinoecismo ático no período arcaico. $\mathrm{O}$ autor considera que não houve a consolidação da unificação do território ático até o final da tirania de Pisístrato e que à discussão sobre o tema está interligada a construção tardia da narrativa mítica de Teseu como herói grego a percorrer o território ático promovendo a unificação ${ }^{18}$. Victor Ehrenberg considera que o processo de unificação da Ática tornou-se um tema de difícil explicação diante da ausência de uniformidade entre as tribos jônicas e dóricas como nos revela as suas respectivas

\footnotetext{
${ }^{18}$ Stuart, DAWSON. Rethinking Athenian Democracy. Melbourne: Australia, 2006.p.12.
} 
denominação, tal fato leva o autor a considerar que o processo ocorreu a partir do sinoecismo atribuído ao herói mítico Theseu ${ }^{19}$.

O processo de formação do território ático detém dialogo como temo Dark Age, período de ausência de documentação textual e escassez de informação arqueológica. Para Carol Thomas e Craig Conant no livro Citadel to City-State: The Transformation of Greece, 1200-700 B.C.E., o termo Dark Age se refere ao final da realeza micênica até o período da adoção do alfabeto. Entretanto, Paul Cartledge no Ancient Greece: A History in Eleven define a aplicação do termo para o período entre o IX e o VII a. C., o autor justifica que o termo dark não está relacionado à ausência da escrita entre os gregos, mas à escassez de assentamento, à dificuldade em localizar as pequenas aglomeraçóes populacionais empobrecidas que estavam dispersas no amplo espaço geográfico grego $^{20}$.

Para John van Antwerp-Fine, parte dos scholars consideram que o território ático foi alvo de um processo de integraçáo a partir do período micênico. As evidencias se pautam na inserção de basileus e famílias nobres de diferentes regiōes da Ática, admitidos como integrantes do conselho real. O autor considera ser esse o início do status de mobilidade dos bens nascidos considerados de eupátridas (PLUTARCO, Vida de Teseu, 25). Neste período, pode estar em embate a busca da hegemonia entre os jônios com Theseu e os dórios com Héracles, seguido da incorporação da região de Eleusis no século VI a. C. com a divindade Demeter e Perséfone ${ }^{21}$. Como conjeturamos a partir de Frederick Elliot Winter, a integração da ática assim como da região de Eleusis ocorreu através do sinoecismo cujo período é questionável. Pode ter ocorrido no período da realeza micênica, assim como no VIII a. C., o fato é que outras regiōes do território ático foram agregadas formando uma região comum no qual Atenas tornou-se o centro do poder.

\footnotetext{
${ }^{19}$ Victor, EHRENBERG. From Solon to Socrates.New York:Routledge, 2011.p.41.

${ }^{20}$ Paul, CARTLEDGE. Ancient Greece: A History in Eleven Cities. Oxford: Oxford University Press, 2009.p.30.

${ }^{21}$ John Van, ANTWERP-FINE. The Ancient Greek. A critical History. New York: Harvard, 1985.p. 175 .
} 
A unificação da ática foi citada na Iliada (II, 546) e descrita por Tucídides (II, 15.1) ao relatar que, originalmente, a Ática estava dividida em diversas poleis e Theseu encerrou as atividades das pritaneia e bouleteria locais assim com as magistraturas, centralizando-as na polis de Atenas. Para Morgen Hansen, Theseu e a narrativa da unificação da Ática tornaram-se o único exemplo narrado de sinoecismo que náo foi acompanhado de transferência e realocação da população ${ }^{22}$. John van Antwerp-Fine já afirmava que a grande maioria dos habitantes permaneceu em suas comunidades de nascimento e tal fato deveria ser denominado de sympoliteia/junto a polis e não sinoecismo ${ }^{23}$. Consideramos que termo deixa transparecer que foi aplicado para designar o ato de quatro regióes terem sido reunidas para viverem juntos, ou seja, formando uma Tetrapoleis (Maratona, Tricorintos, Oinoe e Probalinthos).

Entretanto, Morgen Herman Hansen nos alerta que os documentos antigos como Isocrates (X, 35), Diodoro da Sicilia (IV, 61,8), Plutarco (Vida de Teseu, 24) que relatam sobre o tema nos apontam para o termo sinoecismo que se materializou no Ritual da Synoikia ${ }^{24}$. O ritual indica a disposição dos habitantes da Ática de construir o imaginário social no sentido de viver juntos/synoikein (syn/juntos oikein/oikos/morada) já em processo desde o período do Dark Age ${ }^{25}$. Entretanto, devemos reconhecer a dificuldade em comprovar o processo de unificação tanto física quanto cultural, pois as evidencias arqueológicas não fornecem suportes necessários para a confirmação do processo de aglomeração das poleis ática. Considerando as informaçóes textuais, a Ática foi unificada no período da realeza micênica, seguida de um colapso na Idade do Bronze, porém no Protogeométrico tardio, 950 a 800 a. C., Atenas configura-se como centro de poder administrativo.

Hans van Wees considera que a historiografia ortodoxa analisa a sociedade grega a partir da realeza palaciana de onde estabelece a relação de

\footnotetext{
${ }^{22}$ Mogens Herman, HANSEN. An Inventory of Archaic and Classical poleis. Oxford: Oxford University Press, 2004.p.624.

23 John Van, ANTWERP-FINE. The Ancient Greek. A critical History. New York: Harvard, 1985.p. 125.

${ }^{24}$ Mogens Herman, HANSEN. An Inventory of Archaic and Classical poleis. Oxford: Oxford University Press, 2004.p.625.

${ }^{25}$ Robert, PARKER. Athenian Religion: a history.New York: Clarendon Press, 1997.p.13.
} 
parentesco formando uma estrutura tribo ou fratria ou clã. $\mathrm{O}$ autor aponta como matriz dessa abordagem a poesia épica e a tradição oral ao construir o imaginário social a partir dos heróis e mitos que ultrapassam as açóes humanas. Robert Parker indica que essa vertente tem por principio a formação da polis a partir da reunião de indivíduos e seus dependentes consanguíneos, mas, há também os não consanguíneos. Parker acrescenta que a população da Ática era distribuída em quatro tribos/phylai cujos nomes indicam a descendência da comunidade jônia oriunda de Miletos, Efesus e Samos. As phylai não seriam unidades independentes, mas uma subdivisão inserida em um grande grupo compostos de unidade de famílias que interagiram na ação militar e religiosa formando a comunidade poliades ${ }^{26}$.

Denis Roussel na obra Tribu et Cité considera que os genoi atenienses eram formadps por grupos de eupátridas, ou seja, da aristocracia que desde o período de Draco vinha sendo pressionada por outros segmentos sociais denominado pelo autor de "genus plebeus" 27 . Esses buscavam adquirir um lugar de fala junto à phratria ao lado dos eupátridas e no período clássico eram identificados pelo nome da profissão que exerciam na polis.

A identificação desse segmento social torna-se necessário para seguirmos a identificação da formação do quarto segmento social da classe censitária instituída por Sólon e que será à base de apoio de Clistenes, Themistocles e Péricles. O autor afirma que esse segmento social estava organizado, até ao VI século, de acordo com o esquema descrito por Aristóteles na Constituição de Atenas e o genos seria uma organização fechada cuja participação era exclusiva dos gennetes, ou seja, estava vedada aos estrangeiros e não eupátridas. No final do século VI, grande parte da população ateniense estaria fora das instituiçóes tradicionais. Os atenienses não gennetes e inseridos na phratria de Clistenes eram os descendentes de estrangeiros e libertos de períodos precedentes ${ }^{28}$.

\footnotetext{
${ }^{26}$ Ibidem, p. 17.

${ }^{27}$ Denis, ROUSSEL. Tribus et Cité.Paris: Université de Besançon, 1976.p.78.

${ }^{28}$ Ibidem, p.80.
} 
Em relação à organização sócio-politica, os atenienses visavam responder a uma exigência de uma comunidade em processo de diversificação de atividades e participação. Aristoteles define os 360 genoi formados a partir de trinta homens adultos, fato que nos remete a formação de defesa dos dez mil e oitocentos homens efetivos e disponíveis para o combate em terra através da armada dos hoplitas, ou seja, a infantaria ateniense que promoveu a revolução hoplitica ${ }^{29}$. Podemos dizer que o sistema identificado, colocado em prática e em funcionamento, no final do VI a. C., estava relacionado ao processo de desarticulação da armada hoplitica instituída por Pisístrato. No final desse período, a reorganização do corpo cívico, através da reforma territorial, foi acompanhada da rearticulaçáo da armada dos hoplitas.

Entretanto, os antigos genoi tradicionais tornaram-se pouco expressivos com fragilidade de participação, pois o termo genos adquire uma nova conotação no sentido técnico ao designar uma corporaçáo religiosa e não consanguínea ${ }^{30}$. Os membros do genos reconhecido como gennetes ou homogalactes eram reconhecidos devido à relação de parentesco, na nova designação, o termo passa a indicar os indivíduos que habitavam uma mesma regiáo formando uma comunidade poliades com santuários e lugares de culto comum.

Diante das controversas, a alternativa nos leva a supor que o modelo de sistema tribal jônio criado do outro lado do Mar Egeu no período do VIII a. C., foi copiado por outras comunidades devido à relação de parentesco real ou fictício formando uma proximidade cultural com genos gerador. A introdução do sistema tribal em Atenas, se foi invenção ou imitação a partir da Jônia, não vem ao caso, mas se tornou um processo difícil de estabelecer a sua emergência assim como o possível período do processo de unificação da Ática.

Em relação às reformas de Clistenes, $\mathrm{S}$. Dawson considera que esse não teve por objetivo construir uma ideologia democrática, mas sim resolver problemas sociais de disputa e rivalidade entre facçóes de famílias aristocratas que buscavam a liderança regional nos últimos anos da tirania dos

\footnotetext{
${ }^{29}$ Ibidem, p.82.

${ }^{30}$ Idem.
} 
pisistratidas $^{31}$. A matriz desta vertente parte da Constituição de Atenas ao firmar que transformação territorial ocorreu quando os atenienses foram divididos em quatro tribos, foram instituídos os basileus seguidos da conformação de um regime que ocorreu na época de Theseu (Constituiçáo de Atenas, 41.2). Entretanto, Stuart Dawson considera não haver razão para delimitar o inicio do sinoecismo, tendo em vista que esse foi um fenômeno de construção tardia que ocorreu por relação de parentesco e/ou proximidade geográfica. $\mathrm{O}$ autor acrescenta que a variedade de evidencia indica que não houve unificação até Pisístrato ter assegurado a tirania ${ }^{32}$.

Em suma, antes de 570 a. C., segundo Plutarco, Atenas e a Ática continuavam a ser um aglomerado de aldeias muradas, permanecendo regionalmente dividida no período de Sólon a Pisístrato (Plutarco, Vida de Sólon, 13.11). A estabilidade da região dependia da coalizão das forças instáveis que repousava nas mãos das famílias de aristhoi, embora, Pisistrato tenha forçado o estabelecimento de uma centralização de poder.

Entretanto, com a presença da Boulé dos Quinhentos, acreditamos que podemos afirmar a presença da unificação do território ático efetuado por Clístenes. Charles Hignett na obra $A$ history of the Athenian constitution to the end of the fifth century B.C, 1970 considera que o processo de unificação da Ática deve ser compreendido como uma açáo política de ratificação do controle político e náo como um movimento que visava colocar o demos no centro da tomada de decisão.

${ }^{31}$ Stuart, DAWSON. Rethinking Atheniean Democracy. Melbourne: Australia, 2006.p.13.

${ }^{32}$ Ibidem, p. 15. 